\title{
Learner Autonomy in Developing Countries
}

\author{
Richard Smith, Kuchah Kuchah, and Martin Lamb
}

\begin{abstract}
Learner autonomy may have special relevance now in developing countries, where a dissonance often exists between what formal education offers and what many learners want or need. Globalization and its technologies are providing new means of accessing knowledge, but school language lessons remain largely unchanged. Almost by default, successful language learners in developing country contexts are autonomous learners who can exploit out-of-school resources, while some of the most effective pedagogy involves promoting autonomy as a means of confronting low-resource challenges. This chapter argues for more research into both these phenomena, in order to increase understanding of them and to enable identification of principles for practice. It also emphasizes the need for such research to be conducted with and by local teachers and learners.
\end{abstract}

\section{R. Smith $(\bowtie)$}

Centre for Applied Linguistics, University of Warwick, Coventry, UK

K. Kuchah

Department of Education, University of Bath, Bath, UK

M. Lamb

School of Education, University of Leeds, Leeds, UK

(C) The Author(s) 2018

A. Chik et al. (eds.), Autonomy in Language Learning and

Teaching, https://doi.org/10.1057/978-1-137-52998-5_2 
Keywords Learner autonomy - Developing countries • Difficult circumstances • Appropriate methodology • Mobile learning • Teacher-research • Researching with children

\section{INTRODUCTION}

Learner autonomy as a concept has its origins in Europe and, for a time, there were even questions about whether it had relevance for educational cultures elsewhere. This chapter suggests that it may, in fact, have particular relevance now for learners in developing countries, and specifically in less well-resourced contexts. We should recognize at the start that 'developing countries'-using the broadly accepted, though not unproblematic (see, e.g. Khokhar, 2015), definition of such countries as those with a lower standard of living, undeveloped industrial base and moderate-to-low Human Development Index (HDI) relative to others-are themselves highly diverse contexts, presenting stark contrasts between urban and rural areas, for example, and between private and public institutions. Our focus in this chapter will be mainly on those settings within developing countries which are less well-resourced, and where official provision of education (whether publicly or privately funded) is currently most deficient in enhancing the life chances of young people. In this chapter, we report on some of the research which has been undertaken with as well as 'into' learners and teachers in such contexts, and we highlight areas which would benefit from further research.

\section{Evidence of Autonomy in Developing Country Contexts}

In the past, 'learner autonomy' has often tended to be associated with technology-rich self-access centres ('resource centres'), and with technology in general. Indeed, autonomy research has been mainly carried out with learners in well-resourced Western or East Asian settings. In apparently 'under-resourced' contexts, its importance may have seemed less salient. Nevertheless the affordances that are available in such settings should not be underestimated, as we shall see. At the same time, it seems particularly important to study autonomy in developing country contexts, given its relevance in many learners' lives. 


\section{Signs of Autonomy in Learner Beliefs and Behaviours}

As part of a broader study in Cameroon, Kuchah (2013) set out to elicit from state school primary children aged around 11-12 what they thought were good English language teaching practices. Through the use of various participatory approaches to data collection, children, in both urban and rural contexts, were found to be able to identify a number of practices as either good or bad and, in each case, provide reasons for their judgements. For example, they wanted teachers to encourage them to work in groups or pairs to develop their own ideas. They did not like teachers who explained every detail to them, but instead wanted to be challenged to think for themselves:

JosephineB5: I like when the teacher is explaining something, but she should not explain it all. I like that she should allow some for us to go and find out and come and explain in class.

$[\ldots]$

GraceGl: If she ask us to go and find out, it will make me to make an effort to learn [...] it is not good when the teacher tells us everything; it is good that we should also do our homework so that we can learn on our own and understand. (ibid, pp. 149-150)

Among the good practices identified by children, a few were particularly absent from the practices of their teachers. Children's desire for homework which would enable them to engage in independent learning outside the school environment was one case in point. Another was the desire of some children to be involved in providing teaching materials/aids because they thought the process of producing or finding such materials would help them develop a better understanding of what they study in class:

AlbertoG5: If we bring the things to class, it will be more interesting because we will see if we can remember the names of all the things that we need to cook [the food] [...] then it will be easier for us to understand how to write the composition because we already know how to cook it. (ibid, p. 151)

Hamid and associates' work in Bangladesh (Hamid \& Baldauf, 2011; Hamid, Sussex, \& Khan, 2009) has pointed to a similar dissonance between state provision of English and what young people desire:

Students' voices help us to understand how the discourses of the benefits of English lead learners in developing areas to struggle with English with their 
limited resources and how the teaching and learning of English have come to rely on non-curricular and non-methodological means (i.e. private tutoring) in the context of poor performance of the public sector English teaching. (Hamid \& Baldauf, 2011, p. 214)

Given the social inequities of this state of affairs - with only children of the better off likely to achieve any meaningful proficiency-Hamid and Baldauf (2011) call for more research into the lives and learning behaviour of young people in disadvantaged areas.

Indeed, while researching the motivation to learn English of young people just entering junior high school in a provincial town in Indonesia, Lamb (2004) was immediately struck by the important role of out-of-class learning. A wide range of activities were reported which involved the use of English: listening to radio programmes in English, listening to and learning pop songs, watching English language films or TV shows (sometimes with subtitles covered), playing computer games, reading English language teenage magazines and novels, studying independently at home, practising English conversation with friends. Even at the age of 12-14, these learners were able to distance themselves from their school English classes, often casting a jaundiced eye over events there: apart from the dull lessons, they were aware that some teachers in the school struggled to speak English fluently themselves. Indeed, the teachers were aware that many learners studied the language independently. One teacher who had done some action research commented:

It's the interesting [idea] that I got from my research at that time, that the students want to study based on their $[\ldots]$ activity, they don't want only to wait $[\ldots]$ on the teacher. (cited in Lamb 2004, p. 238)

Most school teachers were not familiar with the concept of 'learner autonomy', and there was little evidence, either in their talk or their teaching, that they deliberately promoted it. Yet, as Lamb's findings reveal (see also Lamb, 2002), students were able to improve their English language by independent means.

In a later study, in a relatively remote rural area, Lamb (2013) again found that the most motivated Year 8 learners of English exhibited considerable levels of autonomy (as revealed through a large-scale survey in three village junior high schools). Like their urban counterparts, they too listened to English language songs, watched English TV and used computers 
in internet cafes, but their real enthusiasm was for the affordances of mobile phone technology, which by now allowed for relatively easy and cheap access to the internet. They put this facility to various uses: everyone thereby had access to a good quality dictionary, and many also sought out language learning websites to supplement school lessons. Pre-eminently, though, the technology enabled them to set up Facebook pages and establish their own social networks, which sometimes included foreign contacts with whom they would communicate in English. Some were even starting to use English words and phrases in their text messages to Indonesian friends. Lamb (2013) suggests that 'because of its capacity to reach across national borders, [online] social networking appears to legitimate the use of English when in more local domains it may be considered pretentious' (p. 25).

The concept of learner autonomy may, then, have a particular kind of relevance in the developing world, partly because there is such a dissonance between what formal education offers, or can offer, and what many learners want and actually attempt to gain for themselves. In rural parts of Indonesia, as Lamb's research has shown, globalization and its technologies are having the effect of increasing the desire for English among young people and providing novel means of accessing it, while their school English lessons remain largely unchanged, dependent on the textbooks, assessments and the professionalism of their class teacher. This kind of dissonance is probably found in most developing world contexts right now, and how it affects learners' sense of autonomy and their autonomous learning and use of English is worthy of much more study.

\section{Use of ICT as a Possible Focal Point for Research}

In connection with out-of-class learning, a particularly important focus for research in developing country contexts would seem to be the use of technology to enhance learning in remote rural contexts. This was vividly brought to the attention of the ELT profession by Sugata Mitra's plenary talk at the IATEFL conference in April 2014. He shared descriptions of the famous 'hole in the wall' experiments, where children in Indian villages apparently learned how to use computers by themselves, and without any form of scaffolding by adults, and he also drew attention to his more recent work which shows how groups of seven-year-olds can use the internet to teach themselves physics to the level of first year undergraduates. He showed a clip from inside a hut in a poor Indian village, where a 
mother is heard saying about her infant son 'we really want him to become an educated person but it's difficult because of the state of the school'. Mitra's big claim is that cloud technology is now allowing us to bypass the school, which he regards as an anachronistic legacy of Victorian Britain's need for clerks to serve its expanding empire.

The talk provoked a storm of protest among some delegates who believed he was demeaning the status of the teacher, but it raised the interesting question of whether new technologies by themselves can engage and develop learner autonomy in young people. It may be possible to see this happening in rural Indonesia, where relatively cheap smart phones are being used by learners to learn English, or, rather, they are using their English resources to connect to the world via their smart phones and in the process are expanding those resources, almost as a muscle is expanded through regular exercise. How widespread is this phenomenon? Does it occur only where mobile phone technology is relatively cheap? What are young people actually doing in English? Is it only certain individuals, for example those from better off homes, who are using mobile phones in this way, or is it a more general phenomenon? And where does this leave the school teacher, who is not going to lose her job any time soon but may feel threatened by this wave of technical innovation which her pupils can master much better than she can? It is quite possible that further research elsewhere would uncover a similar spread of mobile technology as found in rural Indonesia (see above), with a similar democratizing effect on access to English (for relatively recent evidence, see Tyers, 2015).

The discussion in this section leads us to the first clear research need we wish to highlight:

Research Priority 1 There is a need for more studies of learning and learner autonomy in out-of-class settings in developing countries, with a particular focus on the affordances of mobile phone technology and other types of access to the internet. Such research will have major implications for grant-aided development initiatives, for teacher training and for teaching in such contexts.

\section{Engaging Autonomy as Apropriate Pedagogy}

The picture we have so far been painting has been one of some-perhaps many-learners engaging and maybe developing their autonomy in outof-class language learning in situations where schools and teachers are 
struggling to cope. We now look at the frequently very challenging circumstances of classroom learning in developing country contexts, and at how a pedagogy of autonomy has, in some cases, been found to emerge as a kind of 'rescue solution' (Fonseka, 2003).

\section{Difficult Circumstances for Classroom Learning and Teaching}

The state of formal teaching and learning in developing countries is certainly not optimal from participants' points of view, as revealed in a candid account by Lie (2007). Like those in so many developing countries, Indonesian educators face numerous structural problems:

- A rapidly expanding and increasingly diverse pupil population: Lie (2007) compares the privileged students of high-quality schools in metropolitan cities like Jakarta and Bandung to their counterparts in 'the jungles of Kalimantan and Papua' (p. 10) and asks how any centralized curriculum could be expected to meet needs in both settings. Indonesian state school classes typically have around 40 pupils, presenting a wide spectrum of proficiency levels and making it difficult for teachers to establish close relations with individual pupils.

- Pay and conditions for teachers have improved over recent years, but this has followed decades of underinvestment in education, and in teacher professional development in particular (Chang, Shaeffer, AlSamarrai, Ragatz, de Ree and Stevenson, 2014). Language classroom methodology remains largely traditional, with teacher-centred, textbook-based lessons aimed at the staged learning of grammar, vocabulary and reading comprehension, while oral practice is limited to rote repetition of textbook dialogues and teacher-pupil question and answer routines (Marcellino, 2008).

- A third major constraint that Lie (2007) identifies in the formal language education system is a lack of resources, for example in terms of available textbooks, audio/visual materials and ICT support. Although other contexts in the developing world may be much worse off, she argues that the EFL setting, where English is rarely used in the social environment, makes the lack of attractive supplementary learning resources relatively acute. In fact, this situation is changing rapidly, as English is increasingly used in public advertising and signage (Chern \& Dooley, 2014) and mobile phone-based internet services spread rapidly through the country (see above), but 
teachers are not trained to exploit this material and may feel that venturing into these unfamiliar domains could undermine their authority as the fount of language knowledge.

The British educationalist Michael West (1960) coined the phrase 'teaching in difficult circumstances' in relation to settings like these, which are prevalent across the developing world but which have tended to be neglected by language teaching theorists and researchers. This neglect has, indeed, been 'dysfunctional', if we consider that most teaching in the world occurs in such circumstances, as argued by Smith (2011). Of course, classrooms in the public sector in developing countries vary in many ways, but they also tend to share sufficient similarities (relatively low resourcing, large classes, etc.) to be comparable across contexts and to benefit, for now, from their specificities being highlighted with the catch-all term 'difficult circumstances'.

At first glance, the difficult circumstances of teaching and learning in classrooms in the developing world such as those we have described do not seem promising territory for the promotion of learner autonomy. With regard to African contexts, it has been suggested (e.g. by Ampiah, 2008) that because of resource challenges and a lack of appropriate and sufficient training for most teachers in rural communities, transmission-oriented 'chalk and talk' pedagogies are the norm, rendering the notion of autonomy distant from local realities and, potentially, a culturally alienating one.

Indeed, for those who view the concept of learner autonomy as essentially a European one, the very notion of promoting autonomy in developing countries might appear culturally imperialistic, or even neocolonialist, in inspiration-akin, perhaps, to the kind of inappropriate, paternalistic development initiatives described in Zambian economist Dambisa Moyo's (2009) Dead Aid: Why Aid Is Not Working and How There Is Another Way for Africa. Such concerns may have been one reason why, in one of the few articles to consider learner autonomy in relation to an African context, Sonaiya (2002) described it as a form of individualism which was typically western and incompatible with the community-oriented cultures of the Yoruba people.

We now wish to show, though, how the above propositions can be turned on their head. In fact, we shall argue, it is precisely because the teaching and learning circumstances in developing countries tend to be so challenging that engaging and developing learner autonomy can be a pressing priority for participants concerned. 


\section{Practical Reasons for Engaging and Developing Autonomy}

On a dark, chilly evening in November 1812, the Yorkshire mill owner Joseph Rogerson recorded in his diary: 'Mr Humphreys at my father's tonight talking on the best way of establishing a School on the Madras System at Bramley' (cited in Crump, 1931). Mr Humphreys, the pastor at Bramley chapel, was, like many of his contemporaries, struggling to devise a way to teach ever-increasing numbers of children, as the urban population of England surged. The Madras system that he was thinking of importing into his chapel school may have had its origins in a traditional Tamil form of literacy teaching, where a master would instruct older children in how to draw letters and words in sand, and they would then help younger children to write and pronounce them, thereby enabling far more children to learn to read and write than would be otherwise possible. By 1820 there were over 12,000 schools in England using the Madras system, and the man who popularized it, Andrew Bell, has a tomb in Westminster Abbey.

There are many aspects of this system which today we would find oppressive-Bell's primary aim after all was 'instilling principles of religion and morality into the minds of the young' (1797, p. 6)-but the notion that children might learn more from active collaboration with their (near-)peers than by listening in obedient silence to their teacher was one that impressed early-nineteenth-century educators in Britain. In a chapter in which we argue for the importance of learner autonomy in developing country settings, it is worth remembering that the exchange of educational ideas has a long history and is two-way; in fact, as Thompson (2013) points out, in the globalized twenty-first century, it is ongoing and multidirectional, whether it involves 'a Nigerian educator recommending presentational strategies to teachers in the UK or a Brazilian practitioner explaining Freirean approaches in China' (p. 48). Within most global societies there exist diverse, competing agendas for education, and we should not be any more surprised to find evidence of relatively learner-centred pedagogy being practised in African settings, for example, than we would be to hear a British minister of education advocating the return of more teacher-centred whole-class learning (Department for Education, 2013).

Indeed, as Smith (2002) has previously written, autonomy can take different shapes in different cultures and historical contexts, and 'teaching students to learn' is not simply the latest language teaching fashion but 
can be related to deeper, older educational conceptions and traditions. He cites, for example, Quick (1890, p. 421):

The highest and best teaching is not that which makes the pupils passive recipients of other peoples' ideas (not to speak of the teaching which conveys mere words without any ideas at all), but that which guides and encourages the pupils in working for themselves and thinking for themselves.

In the history of western education, then, a focus on developing learner autonomy is not as new as is commonly supposed, nor should we be surprised to find cases of teachers outside western countries engaging and/or developing students' autonomy without having been influenced by the post-1970s 'learner autonomy movement'.

As the early-nineteenth-century example at the head of this section also shows, in developing country contexts where education is in a rapid state of development and where teachers and physical resources are in short supply (in these respects, England was at the time, after all, the epitome of a 'developing country'), teachers may actually need to tap into and engage the existing autonomy of students to a greater extent than in betterresourced settings. Indeed, certain educationalists have previously highlighted the particular relevance to large classes in developing country contexts of what we might nowadays recognize as an autonomy-oriented approach. Michael West himself emphasized that:

the larger the class and the more difficult the circumstances, the more important it is to stress learning as the objective. And the higher the elimination [i.e. 'drop-out'], the more necessary it is to do so: if a pupil has learnt how to learn he can go on learning afterwards. $(1960$, p. 15)

Thus, engagement of learner autonomy can be seen as an eminently appropriate approach in difficult circumstances, for example, large classes with diverse student needs (see Smith, 2003) and/or few resources (see Fonseka, 2003). With regard specifically to problems posed by large classes, Zakia Sarwar has emphasized the value of group work and project-based learning in Pakistan (see Sarwar, 2001; Smith, 2008). Latterly, she explicitly came to ally this approach with the autonomy movement, as has Amritavalli when describing a successful practice of 'maximising learner autonomy' by enabling choice of extensive reading materials in the 'deprived circumstances' of an Indian primary school (Amritavalli, 2007). As what he calls a 'rescue solution' in a situation of lack of printed materials, Sri Lankan 
educator Gamini Fonseka (2003) also came to theorize from an autonomy perspective his experience of getting children to memorize songs and work with these as a source of language learning input.

As documented and discussed further in Kuchah and Smith (2011), the practical worth of an autonomy-oriented approach is borne out by the experience of one of the authors of this chapter-Kuchah Kuchah-in Cameroon. Sonaiya's (2002) argument about the incompatibility of autonomy with an African 'communal aspect of learning' (cited above) was disproved in this experience, since it was precisely via a collective effort that Kuchah and his students were able to develop autonomous learning as a rescue solution to the challenges they faced, namely, large classes of more than 200 teenagers in temperatures above $46{ }^{\circ} \mathrm{C}$ and with almost no textbooks to rely on. Students were enabled to work with learning materials they had helped provide as well as with negotiated pedagogic practices that helped them and their peers to attain learning objectives that were both relevant to them and consistent with the syllabus requirements.

Thus, a number of educators familiar with the difficult circumstances of classrooms in developing country contexts have, at different times, developed and advocated autonomy-oriented practices as a way to overcome practical difficulties, even though they were not, in most cases, actually inspired by learner autonomy theory. Thus, they were engaged in pedagogies of autonomy though not for autonomy, according to the distinction made by Kuchah and Smith (2011).

It is probable that there are many other such cases, yet to be described and identified, whose documentation would be of great use within the kind of context-sensitive 'enhancement approach' to teacher development described in Kuchah (2013), advocated by the Teaching English in Large Classes research and development network (bit.ly/TELCnet-home) and promoted in the current University of Warwick 'Teacher-research for difficult circumstances' impact initiative (warwick.ac.uk/trdc). Along with Kuchah (ibid.), Smith, Padwad and Bullock (forthcoming) provide examples of how stories of success can usefully be shared in a teacher development workshop situation, while Lamb and Wedell (2013) have highlighted the value of capturing and sharing the experiences of what they term 'inspiring teachers' in China and Indonesia.

Taken together, these concrete examples constitute a firm argument against the idea that autonomy-oriented pedagogy is inappropriate in developing country contexts or that it is necessarily an imposed western ideal-in fact, we have seen the argument reversed: a pedagogy of autonomy can be 
very appropriate indeed, precisely because it works with the 'social autonomy' (Holliday, 2003) that learners bring to the classroom. Thus, a pedagogy of autonomy can be viewed as a kind of 'becoming-appropriate methodology' par excellence, as Smith (2003) has previously argued.

To be quite clear, we are not advocating any specific form of pedagogy. Subscribing to the contextualist paradigm of educational reform (Elliott, 2014), which emphasizes the cultural situatedness of all educational practices, we are well aware of the difficulty in transferring teaching approaches from one context to another, and indeed of the long history of failure in the export from the west of 'learner-centred' educational approaches (Schweisfurth, 2011). Rather, we are suggesting that autonomy-as the ability to take control of one's own learning-is an essential characteristic of all successful learners and can be found everywhere if we know how to look. A previous volume (Palfreyman \& Smith, 2003) showed how learner autonomy can and does take varied forms in different national, institutional or sociocultural settings, and can be cultivated in diverse institutions and classrooms. As Holliday $(2003,2005)$ points out, however, it is often missed by educators, especially those looking with western eyes, because it may not be displayed in forms that they recognize (e.g. assertive expression of personal ideas), or in the educational contexts that they expect (e.g. classrooms), nor articulated in the same terms by teachers. Sometimes it can be seen outside the classroom as countering what goes on in the classroom (as in the preceding section), but it can also be tapped into within the classroom by certain educators, as we have illustrated in the present section.

Research Priority 2 There is a need for more research into and sharing of success stories of teaching in low-resource classrooms, to assist in building appropriate methodology from the bottom upwards. Cases of successful teaching should be viewed and analysed on their own terms, but can also provide fertile ground for understanding how 'social autonomy' can be engaged in particular contexts.

\section{NeEds FOR BOtTOM-Up Research WITH AND/OR Br Teachers and Learners Themselves}

We have argued that identifying and describing cases of autonomy outside class and inside class is useful, our underlying assumption being that this will not just help to fill a 'theoretical' gap but can have significant practical implications, especially where teacher development-as touched on in the 
last section-is concerned. However, the question arises of who should do the research that is needed if learner autonomy is to be better understood, engaged and enhanced in outside-class and classroom contexts in the developing world.

The question is an important one partly because there is an everpresent danger of inappropriate imposition of ideas onto educators in the contexts concerned. For example, however well-intentioned he may individually have been, and however experience-based his ideas, Michael West was himself a colonial educator (in what is now Bangladesh), and some of his suggestions come across as rather paternalistic for this reason (Kuchah, Padwad and Smith, in process). There are needs for self-conscious decentring, indeed decolonizing of English language teaching methodology and discourse, in particular (ibid.), and this is not necessarily best served by academic studies emanating from northern/western universities. Locating the control of research in the hands of academics from the countries concerned is not by itself adequate as a solution either, although it may be a step in the right direction, since there has been a worldwide 'neocolonization' of English language teacher development by applied linguistics, even as former colonies have gained political independence. Divorces between theory and practice are therefore just as prevalent in developing countries as elsewhere (see, e.g. Clarke 1994), and overly academic studies, even if carried out by researchers in the countries concerned, are unlikely to have much resonance with or impact on people there.

Adopting a participant-centred approach to research and to associated teacher development therefore appears necessary, indeed appropriately autonomy-oriented, in developing country contexts. This might involve two aspects, relating to participation and actual control by teachers and by learners themselves, considered now in turn.

\section{Research with and by Teachers}

One possibly appropriate alternative to purely academic research is 'Teacher Association (TA) Research', as developed by Smith and Kuchah (2016) with the Cameroon English Language and Literature Teachers Association (CAMELTA). By analogy with 'teacher-research', TA research is defined as 'systematic inquiry which is derived from members' expressed priorities and officially endorsed by a TA, and which engages members as active participants in what they see as a collective project to improve 
understanding and practice' (Smith \& Kuchah, 2016, p. 215). Academic expertise can be enlisted in the service of such a project, as has occurred in the Cameroonian case, but control of the ongoing research remains in the hands of the TA itself, assuring relevance to the lives of members. So far, in line with research priority 2 (above), CAMELTA research has uncovered a large number of success stories and solutions to common classroom problems which, shared across the membership, provide useful starting points for members' continuing professional development. The idea emphasized above, that successful practice in difficult circumstances is often relatable to engagement of learner autonomy, appears to find strong support in the data gathered so far (see the CAMELTA website, http:// camelta-cameroon.weebly.com/resources--useful-links.html). TA members have given some quite clear indications, additionally, that they feel their own autonomy has been enhanced via engagement in the project (see, for example, Smith and Kuchah, 2016).

The engagement and enhancement of teachers' own autonomy in relation to their professional development can, of course, be seen as a major aim of practitioner research generally (cf. Dikilitaş \& Griffiths, 2017; Smith \& Course, 2014). A major issue, though, is whether teacherresearch is actually feasible, in particular in the kinds of difficult circumstance we have been describing (one aspect of such circumstances often being the high number of hours teachers have to devote to teaching and marking, and the fact that they may need to engage in private tutoring and/or work at more than one institution in order to make ends meet). While collective, open-ended questionnaire-based TA research was developed in the Cameroon case as an alternative to more individualistic, possibly unfeasible teacher-research, a happy medium appears to have been struck in another recent Teacher Association project, this time one organized by the All-India Network of English Teachers (AINET) in 2015-16. Here, the difficulties of lack of time and support for individual teacher-research in difficult circumstances appear to have been successfully addressed via volunteering and much collaborative activity within the association.

Other approaches to making teacher-research appropriate in relatively difficult circumstances have included the discussion-based practice described by Naidu, Neeraja, Ramani, Sivakumar and Viswanatha (1992) (again, a collective, collaborative approach); Exploratory Practice, as developed in Rio de Janeiro (see Allwright \& Lenzuen, 1997; Allwright, Lenzuen, Mazzillo \& Miller, 1994); and Exploratory Action Research, as 
developed originally in the context of the Chilean Champion Teachers programme (Smith, 2015; Smith, Connelly \& Rebolledo, 2014). In all three of these approaches, clarification and exploration of a problematic situation or puzzle is prioritized over action for change, and research procedures are not presented as an additional burden but as something teachers can integrate into a busy teaching schedule, while nonacademic, teacher-friendly sharing of findings is also emphasized. Thus, not only teaching but also teacher-research requires procedures to be specifically tailored to difficult circumstances.

\section{Research with and by Learners}

As with research involving teachers (above), a genuinely autonomyoriented approach to research in developing country contexts would involve not so much research on or into learners as research with them, and even by them. As already indicated above, Kuchah's (2013) research involved participative, child-friendly research methods enabling rich data to be gathered which revealed signs of autonomy in inside-class and outside-class language learning (see also Kuchah \& Pinter, 2012). As would be expected, many of the children indicated that they liked lessons in whose practice exercises they scored good marks. But the excerpt below shows something different:

KinivoB1: This is my best lesson... I had a zero in the exercise.

Harry: So it was your best lesson because you had a zero?

KinivoB1: No, because [the teacher] did not tell us what to do, so I had zero. But after, my friend explain[ed] to me what I was supposed to do, and I know it very well now.

Harry: Wait a minute. Who helps you to understand more? Your friend or your teacher?

KinivoB1: I understand better when my friend explains to me. (Kuchah, 2013, p. 136)

Whether we look at this as an example of peer support, collaborative learning or whatever terminology we assign to it, the point is that it was the child's personal decision to seek for help from her friend and, in doing so, she was able to understand the lesson better. In a large class of 103 10-/11-year-olds, this is just one instance of autonomous (or teacherindependent) learning which could be built on further. 
Pedagogies of autonomy can, indeed, be built up on this basis of accessing learners' voices in a child-friendly and context-sensitive manner. Of course, this is not a new finding for teachers who have been engaged in pedagogy of/for autonomy, but if more research findings can be shared which highlight the existence and rationality of students' opinions regarding their learning, more teachers could be expected to take notice.

Teachers can and do- of course-discover learners' autonomy for themselves, and one way this discovery can occur is, precisely, via the kind of teacher-research approach we have described above. Engagement in teacherresearch which involves exploration of students' perceptions can lead teachers to understand learners better for themselves-perhaps the major outcome of the Chilean Champion Teachers project, for example, has been that teachers learn to listen to and thereby understand their students better than before (see Rebolledo, Smith \& Bullock, 2016; Smith et al., 2014).

Indeed, in recent manifestations of Exploratory Practice (e.g. Allwright and Hanks, 2009), the learner is conceived of as a researcher-or explorer of classroom life-just as much as the teacher. Pinter, Mathew and Smith (2016) have additionally shown that pre-teenage children can be engaged appropriately and successfully in activities whereby they themselves act as coresearchers, in the context of teacher-research activity in Indian primary classrooms. Not only are interesting findings produced for a wider readership, the children themselves also benefit from the research process in that their autonomy is engaged and developed even as it is explored. Thus, finally, we wish to emphasize the importance in autonomy-oriented research of considering in whose interests the research is taking place and ensuring that participants' interests are both protected and well-served, ideally via involvement of them in controlling and carrying out the research, to their own immediate and/or long-term benefit.

Research Priority 3 Engage teachers and learners themselves in research which both respects and contributes ethically to the development of their own autonomy, enabling expression of their voices and engagement of their agency, and avoiding research simply 'on' or 'into' them.

\section{CONCLUSION}

We have indicated some studies which have begun to treat the area of learner autonomy in developing countries, but we have also pointed out that much remains to be researched, shown why it is worthwhile to do 
such research and indicated how it might be approached. We think there is justification in considering 'developing countries' as a distinct type of context which has so far been under-researched, despite the dangers of essentialization involved.

As we have seen, cases of success from teachers' and learners' own perspectives can be usefully gathered, analysed and disseminated with a view to enhancement of professional practice. One central issue worthy of further reflection and research concerns the role of teachers: does it matter whether they actually do try to foster learner autonomy deliberately or whether learner autonomy is a kind of by-product of the limitations of school language education? Another important area for research concerns the potential benefits of using ICT to enhance learning in remote rural contexts.

Research in these areas will, crucially, need to involve teachers and learners themselves. Indeed, a central theme has been the importance of participants becoming involved centrally as actors in research, appropriately to an autonomy paradigm, not just having research done 'into' or 'onto' them. We have, in other words, highlighted the value of learners and teachers themselves being engaged in explorations of their learning and teaching lives-especially in the light of concerns that autonomy should not be just the latest in a long line of fashionable academic concepts to be 'dumped' inappropriately in the developing world. As autonomy researchers we need to be conscious of the power relations involved in research and not just in teacher education and pedagogy.

Finally, in this chapter, we have mainly discussed how aspects of the situation in developing countries might form a context for the development of learner and, to some extent, teacher autonomy. However, it would be interesting to consider, additionally, to what extent a greater engagement and enhancement of learner and teacher autonomy could contribute to the overall development of the countries in question. After all, the word 'developing' implies a more positive perspective than the deficit indicators which are typically used to define a 'developing country' (lower standard of living, undeveloped industrial base and moderate-to-low Human Development Index (HDI) relative to other countries). The relationship between learner/teacher autonomy and developing standards of living, an improved industrial base and raised HDI measures, attainment of Sustainable Development Goals in the area of quality of educational provision and the identification of paths for development which are internally generated, could usefully be considered as additional areas for further investigation. 
Acknowledgement We are grateful to David Palfreyman for originating the thinking in the final paragraph, by means of his useful comments on an earlier draft of the chapter. We also acknowledge the support of the United Kingdom Economic and Social Research Council (grant number ES/M500434/1).

\section{References}

Allwright, D., \& Hanks, J. (2009). The developing language learner: An introduction to exploratory practice. Basingstoke, UK: Palgrave Macmillan.

Allwright, D., \& Lenzuen, R. (1997). Exploratory practice: Work at the Cultura Inglesa, Rio de Janeiro, Brazil. Language Teaching Research, 1(1), 73-79.

Allwright, D., Lenzuen, R., Mazzillo, T., \& Miller, I. K. (1994). Integrating research and pedagogy: Lessons from experience in Brazil. CRILE Working paper 18, Lancaster University.

Ampiah, J. G. (2008). An investigation of provision of quality basic education in Ghana: A case study of selected schools in the central region. Journal of International Cooperation in Education, 11(3), 19-37.

Amritavalli, R. (2007). English in deprived circumstances: Maximising learner autonomy. Bangalore, India: Foundation Books.

Bell, A. (1797). An experiment in education made at the male asylum of Madras. Suggesting a system by which a school or family may teach itself under the superientendance of the master or parent. London: Cadell and Davies.

Chang, M. C., Shaeffer, S., Al-Samarrai, S., Ragatz, A. B., de Ree, J., \& Stevenson, R. (2014). Teacher reform in Indonesia: The role of politics and evidence in policy making. Washington, DC: The World Bank.

Chern, C.-L., \& Dooley, K. (2014). Learning English by walking down the street. ELT Journal, 68(2), 113-123.

Clarke, M. A. (1994). The dysfunctions of the theory/practice discourse. TESOL Quarterly, 28(1), 9-26.

Crump, W. B. (1931). The Leeds Woollen industry, 1780-1820. Leeds, UK: The Thoresby Society.

Department for Education. (2013). Michael Gove speaks about the importance of teaching. https://www.gov.uk/government/speeches/michael-gove-speaksabout-the-importance-of-teaching. Accessed 18 July 2017.

Dikilitaş, K., \& Griffiths, C. (2017). Developing language teacher autonomy through action research. Cham, Switzerland: Palgrave Macmillan.

Elliott, J. G. (2014). Lessons from abroad: Whatever happened to pedagogy? Comparative Education, 50(1), 27-44.

Fonseka, G. (2003). Autonomy in a resource-poor setting: Enhancing the carnivalesque. In D. Palfreyman \& R. Smith (Eds.), Learner autonomy across cultures: Language education perspectives (pp. 147-163). Basingstoke, UK: Palgrave Macmillan. 
Hamid, M. O., \& Baldauf, R. B. (2011). English and socio-economic disadvantage: Learner voices from rural Bangladesh. Language Learning Journal, 39(2), 201-217.

Hamid, M. O., Sussex, R., \& Khan, A. (2009). Private tutoring in English for secondary school students in Bangladesh. TESOL Quarterly, 43(3), 281-308.

Holliday, A. (2003). Social autonomy: Addressing the dangers of culturism in TESOL. In D. Palfreyman \& R. Smith (Eds.), Learner autonomy across cultures: Language education perspectives (pp. 110-126). Basingstoke, UK: Palgrave Macmillan.

Holliday, A. (2005). The struggle to teach English as an international language. Oxford: Oxford University Press.

Khokhar, T. (2015). Should we continue to use the term "developing world"? TheDATABlog. The World Bank. https://blogs.worldbank.org/opendata/ should-we-continue-use-term-developing-world. Accessed 15 July 2017.

Kuchah, K. (2013). Context-appropriate ELT pedagogy: An investigation into Cameroonian primary schools. Unpublished PhD thesis, University of Warwick.

Kuchah, K., Padwad, A., \& Smith, R. (in process). Teaching English in difficult circumstances, revisited.

Kuchah, K., \& Pinter, A. (2012). "Was this an interview?" Breaking the power barrier in adult-child interviews in an African context. Issues in Educational Research, 22(3), 283-297.

Kuchah, K., \& Smith, R. (2011). Pedagogy of autonomy for difficult circumstances: From practice to principles. Innovation in Language Learning and Teaching, 5(2), 119-140.

Lamb, M. (2002). Explaining successful language learning in difficult circumstances. Prospect, 17(2), 35-52.

Lamb, M. (2004). 'It depends on the students themselves': Independent language learning at an Indonesian state school. Language, Culture and Curriculum, $17(3), 229-245$.

Lamb, M. (2013). 'Your mum and dad can't teach you!': Constraints on agency among rural learners of English in Indonesia. Journal of Multilingual and Multicultural Development, 34(1), 14-29.

Lamb, M. \& Wedell, M. (2013). Inspiring English teachers: A comparative study of learner perceptions of inspirational teaching. ELT research paper 13-03. London: British Council.

Lie, A. (2007). Education policy and EFL curriculum in Indonesia: Between the commitment to competence and the quest for higher test scores. TEFLIN Journal, 18(1), 1-15.

Marcellino, M. (2008). English language teaching in Indonesia: A continuous challenge in education and cultural diversity. TEFLIN Journal, 19(1), 57-69.

Moyo, D. (2009). Dead aid: Why aid is not working and how there is another way for Africa. London: Allen Lane. 
Naidu, B., Neeraja, K., Ramani, E., Shivakumar, J., \& Viswanatha, A. (1992). Researching heterogeneity: An account of teacher-initiated research into large classes. ELT Journal, 46(3), 252-263.

Palfreyman, D., \& Smith, R. (Eds.). (2003). Learner autonomy across cultures: Language education perspectives. Basingstoke, UK: Palgrave Macmillan.

Pinter, A., Mathew, R., \& Smith, R. (2016). Children and teachers as co-researchers in Indian primary English classrooms. London: British Council.

Quick, R. (1890). Essays on educational reformers. London: Longmans, Green.

Rebolledo, P., Smith, R., \& Bullock, D. (2016). Champion teachers: Stories of exploratory action research. London: British Council.

Sarwar, Z. (2001). Adapting individualization techniques for large classes. In D. Hall \& A. Hewings (Eds.), Innovation in English language teaching (pp. 127-136). London: Routledge.

Schweisfurth, M. (2011). Learner-centred education in developing country contexts: From solution to problem? International Journal of Educational Development, 31(4), 425-432.

Smith, R. (2002). Autonomy, context and appropriate methodology. In F. Vieira, M.A. Moreira, I. Barbosa, \& M. Paiva (Eds.), Pedagogy for autonomy and English learning. Proceedings of the lst conference of the working grouppedagogy for autonomy, University of Minho, 11th-14th March 2001 (pp. 13-23). Braga: University of Minho.

Smith, R. (2003). Pedagogy for autonomy as (becoming-)appropriate methodology. In D. Palfreyman \& R. Smith (Eds.), Learner autonomy across cultures: Language education perspectives (pp. 129-146). Basingstoke, UK: Palgrave Macmillan.

Smith, R. (2008). Taking the bull by its horns: Zakia Sarwar's pro-autonomy approach to large classes in Pakistan. Independence, 44, 7-13.

Smith, R. (2011). Teaching English in difficult circumstances: A new research agenda. In T. Pattison (Ed.), IATEFL 2010 Harrogate conference selections. Canterbury, UK: IATEFL.

Smith, R. (2015). Exploratory action research: Why, what, and where from? In K. Dikilitas, R. Smith, \& W. Trotman (Eds.), Teacher-researchers in action (pp. 37-45). Faversham, UK: IATEFL.

Smith, R., Connelly, T., \& Rebolledo, P. (2014). Teacher-research as CPD: A project with Chilean secondary school teachers. In D. Hayes (Ed.), Innovations in the continuing professional development of English language teachers (pp. 111-128). London: The British Council.

Smith, R., \& Course, S. (2014). Teacher development, teacher-research, and autonomy (Interview). Independence, 61. Pre-publication version: http:// www2.warwick.ac.uk/fac/soc/al/people/smith/smith_r/smith_and_ course_2014.pdf. Accessed 15 July 2017.

Smith, R., \& Kuchah, K. (2016). Researching teacher associations. ELT Journal, $70(2), 212-221$. 
Smith, R., Padwad, A., \& Bullock, D. (forthcoming). Teaching in the low-resource classroom: Voices of experience. London: The British Council.

Sonaiya, R. (2002). Autonomous language learning in Africa: A mismatch of cultural assumptions. Language, Culture and Curriculum, 15(2), 106-116.

Thompson, P. (2013). Learner-centred education and 'cultural translation'. International Journal of Educational Development, 33(1), 48-58.

Tyers, A. (2015). Is digital education easily accessible to Bangladeshi girls? British Council website. http://www.britishcouncil.org/blog/digital-education-easily-accessible-bangladeshi-girls. Accessed 15 July 2017.

West, M. (1960). Teaching English in difficult circumstances. London: Longmans, Green.

Open Access This chapter is licenced under the terms of the Creative Commons Attribution 4.0 International License (http://creativecommons.org/licenses/ by $/ 4.0 /$ ), which permits use, sharing, adaptation, distribution and reproduction in any medium or format, as long as you give appropriate credit to the original author(s) and the source, provide a link to the Creative Commons licence and indicate if changes were made.

The images or other third party material in this chapter are included in the chapter's Creative Commons license, unless indicated otherwise in a credit line to the material. If material is not included in the chapter's Creative Commons license and your intended use is not permitted by statutory regulation or exceeds the permitted use, you will need to obtain permission directly from the copyright holder.

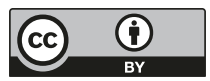

